\title{
AN ANALYSIS OF TEACHER COMMUNICATION BEHAVIORS THAT FACILITATE THE TEACHER-STUDENT RELATIONSHIP IN MIDDLE SCHOOL
}

\author{
Kelli Smithi \\ Dr., Auburn University at Montgomery, \\ United States of America
}

\begin{abstract}
:
This study focused on teacher communication behaviors and teacher-student interactions in the middle school setting as they relate to teacher-student relationships. Thirty-seven teachers and 218 sixth, seventh, and eighth grade students participated in this explanatory sequential mixed methods study. The Questionnaire on Teacher Interaction (QTI) survey was employed to measure ideal teacher communication behaviors and actual teacher communication behaviors in the middle school classroom. Implications for middle school education are discussed, including recommendations for future study with communication behaviors and teacher-student relationships.
\end{abstract}

Keywords: teacher-student relationships, communication behaviors, teacher care, preadolescent students

\section{Teacher-Student Relationships}

Teacher-student relationships are a vital component in the educational system and play a key role in promoting student success. Recent developments have revealed that teachers who put forth the effort to cultivate a relationship with their students are more likely to exhibit increased motivational skills and accomplishments (Allen, Gregory, Mikami, Lun, Hamre, \& Pianta, 2013; Ferreira \& Bosworth, 2001; Gehlbach, Brinkworth, \& Harris, 2012; Ibrahim \& El Zataari, 2020; Tosolt, 2009; Woolley, Strutchens, Gilbert, \& Martin, 2010). Evidence suggests that teacher-student relationships can have a positive impact on student success. However, one primary problem with building these bonds with preadolescent students is it does not take in to account the amount of change that occurs during this time in their lives. For example, Martinez, Aricak, Graves, PetersMyszak, and Nellis (2011) declare that many changes often occur during early adolescence. These researchers state that factors such as "developmental changes, school transitions and experiences, and social influences" have an impact on students' way of

i Correspondence: email vivifoti@gmail.com, pfoti@uniwa.gr 
functioning in the new school setting (p. 526). Andrews and Bishop (2012) provide evidence that challenges such as "figuring out where math class was held, making sure to be ready for PE, coping with constant change of subjects, and getting around the school" (p. 9) can produce a large amount of stress for incoming middle school students. This leads to a further problem when teachers do not identify with students' concerns, in turn causing much fear and trepidation.

A healthy teacher-student relationship can provide students with a feeling of security allowing them to better express themselves, explore possibilities, and become autonomous learners (Hamre \& Pianta, 2006). These bonds, although sometimes difficult to develop, can enhance students' academic and developmental growth (Hamre \& Pianta, 2006) and foster a feeling of connectedness between students and the middle school setting (Sakiz, Pape, \& Hoy, 2012). The value of the bond between teachers and students is essential in keeping students academically engaged (Sakiz, Pape, \& Hoy, 2012).

This study focused on teacher-student interactions in the middle school setting as they relate to teacher-student relationships. Previous research provides evidence that teacher-student relationships have an effect on students' academic success (Anderson, Nelson, Richardson, Webb, \& Young, 2011; Daniels \& Arapostathis, 2005; Hamre \& Pianta, 2006). Building a teacher-student relationship can be challenging (Kesner, 2000). Teachers "often underestimate the importance of their relationships with students" (Sakiz, Pape, \& Hoy, 2012, p. 251) especially in middle and secondary schools. Therefore, students desire to learn from "good" teachers who portray caring behaviors and are genuinely interested in their personal well-being (Ferreira \& Bosworth, 2001 Ibrahim \& El Zataari, 2020). A new approach is therefore needed to investigate communication behaviors exhibited by teachers in a middle school setting in order to better understand factors that affect the teacher-student relationship.

\section{Communication Behaviors}

Previous studies indicate that variables such as socioeconomic status and adolescent development can trigger discipline concerns, as well as force communication barriers between teachers and students (Costa, 2017; Tosolt, 2009). Student attitudes, decisions, and actions are caused by the direct influence of their cultures and beliefs (Newcomer, 2018Lewis, Enciso, \& Moje, 2009). A central component of building relationships between teachers and students is teacher interaction, which is essential in a positive learning environment (Eupena, 2012). It was reported in literature that teachers tend to modify classroom practices "based on observation and knowledge of their students' different backgrounds, interests, abilities, skills, knowledge, family circumstances and peer relationships" (Eupena, 2012, p. 161). These modifications might seem minimal to most, but for students it demonstrates a sense of belonging in a nurturing classroom environment.

A number of authors have recognized a positive teacher-student relationship can be built when students view teachers as having a confident personality, portraying leadership skills, and listening to students' comments, questions, and concerns (Bush \& 
Godden, 2019; Fraser, Aldridge, \& Soerjaningsih, 2010; Wubbels, Levy, \& Brekelmans, 1997). One study concluded the amount of praise, non-verbal support, control in the classroom, and the teacher's ability to make science challenging increased students' attitudes in the learning environment Further, factors such as culture, gender, ability, interest, and peer relationships are perceived differently based on demographics (Eupena, 2012). Hamre and Pianta (2006) stated that girls often relate to their teachers easier than boys. They explain "boys are at a greater risk of relational difficulties in schools" (p. 51). The literature reveals the need to create classroom environments conducive to learning so all students have the opportunity to form a relationship with their teachers.

\section{Communicative Systems Approach}

Over the past thirty years, Wubbels, Brekelmans, den Brok, \& van Tartwijk (2006) have studied interpersonal relationships between teachers and students in a secondary setting using the Communicative Systems approach. This method assumes that communication is constantly occurring, whether it is audible or through body language. The focus of this method is on the consequences of people's actions and how they relate to the content of the communication.

Key tenets of the communicative systems approach focus on the content/relation aspect, levels of communication, and the notion of circularity. Content of communication refers to the specific information that is being conveyed; however, the relation facet informs one on how to react to the content. Three levels of communication make up the systems of communication. The first is a single unit of content and relation, otherwise known as the message. The second level, interaction, is a series of content/relation messages. A pattern is when the interaction level becomes predictable, which is the last level of communication. When "someone's behavior influences someone else and that the behavior of the second person on his or her in turn influences the first" is known to be circularity communication (Wubbels, Brekelmans, den Brok, \& van Tartwijk, 2006, p. 4). For example, a friendly smile from the teacher could induce a student to smile back. The same circular occurrence can also have a negative impact on behavior. Before employing this theory to identify types of communication behaviors between teachers and students, it is necessary to examine the Model for Interpersonal Teacher Behavior, which looks at teacher and student perceptions of communication in the classroom.

\section{Model for Interpersonal Teacher Behavior}

The communications systems approach explains the passage of content from one person to another, in addition to the reactions about that content. This theory was used to develop the Model for Interpersonal Teacher Behavior (Wubbels, Brekelmans, den Brok, \& van Tartwijk, 2006). This model is based on Timothy Leary's (1957) research regarding interpersonal personalities. Leary's model utilizes a coordinate system with two basic dimensions - Dominance-Submission and Hostility-Affection - to explain interpersonal 
personalities. Wubbels, Brekelmans, den Brok, \& van Tartwijk (2006) designed the Questionnaire on Teacher Interaction (QTI) to assess teacher and student perceptions of communication behaviors. The questionnaire identifies pattern level communication, as defined by the communication systems approach, between teachers and students in the classroom. Eight interpersonal behaviors of the teacher can be determined from survey results, which include leadership, helping/friendly, understanding, student responsibility/freedom, uncertain, dissatisfied, admonishing, and strict. Recent studies have used this methodology to identify teacher and student behaviors in the classroom setting (Donker, et. a., 2021; Pennings, \& Hollenstein, 2020; Shukla, Kuril, \& Chand, 2020).

\section{The Present Study}

The overall goal of this study was to identify teacher-student interactions in the middle school setting as they relate to teacher-student relationships. The following research questions guided this phase of the study:

1) What relationship exists between student and teacher perceptions of communication behavior that affect the teacher-student relationship?

2) Is there a difference between ideal teacher communication behaviors and teacher selfperceptions of communication behaviors in the classroom?

3) Is there a difference between teacher self-perceptions of communication behaviors and student perceptions of teacher communication behaviors in the classroom?

4) Is there a difference between ideal teacher communication behaviors and student perceptions of ideal teacher communication behaviors in the classroom?

The researcher analyzed the data using descriptive statistics, inferential statistics, factor analysis, and MANOVA.

\section{Method}

This study presents quantitative viewpoints regarding communication behaviors exhibited by teachers in the middle school setting. The study was conducted in a medium-sized town in Alabama. The school population consisted of 206 sixth grade students, 212 seventh graders, and 203 eighth grade students enrolled for the academic year in which the study took place ( $\mathrm{N}=621$ students). The school employed eight sixth grade teachers, six seventh-grade teachers, four eighth-grade teachers, nine elective teachers, and 10 special education teachers ( $\mathrm{N}=37$ teachers). Some of the teachers (i.e., content and elective) overlapped grade levels because of the lack of funding for more teaching units. Table 1 presents overall demographic data. 
AN ANALYSIS OF TEACHER COMMUNICATION BEHAVIORS

THAT FACILITATE THE TEACHER-STUDENT RELATIONSHIP IN MIDDLE SCHOOL

Table 1: Teacher and Student Demographics

\begin{tabular}{|l|c|c|c|c|c|c|c|}
\hline & Male & Female & $\begin{array}{c}\text { African } \\
\text { American }\end{array}$ & Caucasian & Hispanic & $\begin{array}{c}\text { Asian } \\
\text { American }\end{array}$ & Other \\
\hline Students & 320 & 301 & 224 & 353 & 29 & 5 & 10 \\
\hline Teachers & 5 & 32 & 3 & 34 & 0 & 0 & 0 \\
\hline
\end{tabular}

\subsection{Teacher Surveys}

A critical open question is what relationship exists between student and teacher perceptions of communication behaviors that affect the teacher-student relationship? In order to answer this question, the researcher utilized five sources of data: preexisting deidentified survey data from teachers using the Questionnaire on Teacher Interaction (QTI).

The QTI was administered to 37 faculty members in August at the start of the academic school year using a paper/pencil format. Data analysis from this survey did not provide sufficient evidence of ideal communication behaviors exhibited in the classroom. Therefore, the principal asked the researcher to further explore teacher and student perceptions of communication behaviors in the classroom. The second QTI survey about teacher self-perceptions of communication behaviors was administered in November to the same faculty members using the online survey format, Survey Monkey. Thirty teachers chose to partake in this survey. Out of the participants, three of the surveys were missing data from ten or more survey items; therefore, they were deleted.

Data analysis was performed using a multivariate analysis of variance (MANOVA) test. This statistical analysis was chosen since there were two dependent categorical variables (teacher ideal and self-perceptions) and eight independent variables (leadership, helping/friendly, understanding, student responsibility/freedom, uncertain, dissatisfied, admonishing, and strict). Factor analysis was conducted to identify significant independent variables. Results from these statistical tests facilitated in the development of teacher and student interview questions for phase two of this study.

\subsection{Student Surveys}

Cultures, ethnicities, behavior concerns, and academic challenges are just some of the concerns that teachers deal with on a daily basis. Distinctive groups of students comprehend communication behaviors differently; therefore, it is imperative to acquire data from individual students based on their beliefs about teacher-student relationships (Newberry, 2010). To enhance the data gathered from teachers' surveys, the QTI was administered to middle school students to answer this research question: Is there a difference between teacher self-perceptions of communication behaviors and student perceptions of teacher communication behaviors in the classroom? The researcher used convenience sampling to invite middle school students from the study site to participate in the survey. All participants were reminded that taking the survey was completely voluntary. Prior to conducting the student survey, permission from the middle school principal, Assistant Superintendent of Instruction for the school system, Institutional Review Board (IRB), and parents of students was granted. Students took the QTI survey 
based on communication behaviors in the classroom through the online program, Survey Monkey. The researcher administered the survey during students' elective class. The students were not penalized (by grades or any other form of discipline) if they chose not to take the survey. Approximately $30 \%$ of the entire student population took the survey. The majority of middle school students have many teachers throughout the school day. Therefore, the survey was based on communication behaviors exhibited by their lunch intervention teacher. Every student in the school is assigned to a lunch teacher. This teacher might be an academic or elective teacher of the same grade. For example, a seventh grade student was paired with a seventh grade lunch teacher. In this class, students go to lunch, complete make-up work, or participate in classroom discussions on character education. The lunch intervention teacher served as a mentor, tutor, and classroom management specialist.

An independent $t$-test was conducted to identify the mean differences between teacher self-perceptions of communication behaviors and student perceptions of teacher communication behaviors in the classroom. A Shapiro-Wilks test was used to confirm the assumption of normality was not violated. The researcher also examined skewness, kurtosis, histograms, and normal Q-Q plots to assess normality. The assumption of homogeneity of variance across the two groups for the dependent variable was met by examining Leven's F Test for Equality of Variances in the $t$ - test output. Final results from this statistical analysis were used to guide the researcher in the development of teacher and student interview questions regarding communication behaviors and teacherstudent relationships.

Question four sought to identify the differences between ideal teacher communication behaviors and student perceptions of ideal teacher communication behaviors. Mean differences were determined using results from the preexisting deidentified secondary survey data (teacher ideal communication behaviors) and the student survey (teacher ideal communication behaviors from the student perspective). An independent $t$-test was conducted using SPSS. As noted in question three's data analysis, the same assumptions were analyzed by the researcher. Results from this analysis facilitated the design of teacher and student interview questions for phase two of this study.

\section{Results}

The QTI is comprised of eight independent variables that describe different communication behaviors: leadership, understanding, admonishing, uncertain, helping/friendly, student responsibility/freedom, dissatisfied, and strict. The survey consists of 6 items describing each sector of communication behaviors for a total of 48 items. Exploratory factor analysis was conducted to provide validity of the instrument using principal components analysis with a varimax, orthogonal rotation. Principal component analysis was useful to identify underlying dimensions of variables in construct validity. Of the 48 items selected, there were two components extracted using 
an eigenvalue of 1.00 or greater. The first component accounted for $34.555 \%$ of the variance and the second component accounted for $32.027 \%$ of the variance. Reliability coefficients for the two components were as follows: (a) Component 1, Negative Communication Behaviors, .825, and (b) Component 2, Positive Communication Behaviors, .891. Correlation coefficients for the components are found in Table 2.

Table 2: Reliability Coefficients for the Two Components

\begin{tabular}{|l|c|c|c|c|c|}
\hline Item & $\begin{array}{c}\text { Scale } \\
\text { Mean } \\
\text { if Item } \\
\text { Deleted }\end{array}$ & $\begin{array}{c}\text { Scale } \\
\text { Variance } \\
\text { if Item } \\
\text { Deleted }\end{array}$ & $\begin{array}{c}\text { Corrected } \\
\text { Item-Total } \\
\text { Correlation }\end{array}$ & $\begin{array}{c}\text { Squared } \\
\text { Multiple } \\
\text { Correlation }\end{array}$ & $\begin{array}{c}\text { Cronbach's } \\
\text { Alpha } \\
\text { if Item } \\
\text { Deleted }\end{array}$ \\
\hline & \multicolumn{3}{|c|}{ Component 1, Negative Communication Behaviors } \\
\hline Uncertain & 3.584 & 4.770 & .546 & .370 & .825 \\
\hline Admonishing & 3.269 & 3.445 & .742 & .564 & .735 \\
\hline Dissatisfied & 3.462 & 3.541 & .782 & .614 & .714 \\
\hline Strict & 2.530 & 4.229 & .559 & .375 & .820 \\
\hline & \multicolumn{7}{|c|}{ Component 2, Positive Communication Behaviors } \\
\hline Leadership & 7.445 & 6.403 & .826 & .776 & .836 \\
\hline Understanding & 7.620 & 5.533 & .883 & .809 & .810 \\
\hline Helping/Friendly & 7.500 & 5.596 & .869 & .777 & .816 \\
\hline Responsibility/Freedom & 8.914 & 8.257 & .501 & .299 & .941 \\
\hline
\end{tabular}

Note: Cronbach's Alphas. Component 1: 0.83; Component 2: 0.89

After examination of the principle components, a two-factor solution was retained, which provided the best simple structure. The loadings were all above .67 , which present evidence to the construct validity of the instrument. The underlying elements identified by each component were negative communication behaviors and positive communication behaviors. Principal component factor analysis is presented in Table 3.

Table 3: Principal Component Factor Analysis of the QTI with Varimax Rotation

\begin{tabular}{|l|c|c|}
\hline Item & Component 1 & Component 2 \\
\hline Leadership & -.427 & .779 \\
\hline Understanding & -.476 & .806 \\
\hline Uncertain & .789 & -.009 \\
\hline Admonishing & .802 & -.383 \\
\hline Helping/Friendly & -.407 & .825 \\
\hline Responsibility/Freedom & .076 & .673 \\
\hline Dissatisfied & .870 & -.190 \\
\hline Strict & .711 & -.026 \\
\hline
\end{tabular}

Note: Extraction method: Principal components.

A multivariate analysis of variance (MANOVA) test was conducted to identify the difference in means between the ideal teacher communication behaviors survey and the teacher self-perceptions of communication behaviors survey. This statistical method was chosen because there are eight categorical independent variables (communication scales previously defined by the QTI: leadership, understanding, uncertain, admonishing, 
helping/friendly, student responsibility/freedom, dissatisfied, and strict) and two dependent variables (ideal teacher and teacher self-perceptions).

A multivariate analysis of variance (MANOVA) was examined to determine the effect of dependent variables (ideal teacher and teacher self-perceptions surveys) on the independent variables (leadership, understanding, uncertain, admonishing, helping/friendly, student responsibility/freedom, dissatisfied, and strict). Preliminary assumption checking revealed that data was not normally distributed, as assessed by Shapiro-Wilk test $(p>.05)$. The data was positively skewed; therefore, a logarithmic $\left(\log _{10}\right)$ transformation was applied and the tests of Normality showed normal distributed scores $(p>$.05). Case 26 was deleted due to missing data from ten or more survey questions. There were linear relationships, as assessed by scatterplots and no multicollinearity. There was a statistically significant difference between the ideal teacher communication behaviors survey and the teacher self-perceptions of communication behaviors survey on the combined dependent variables, $F(24,1001)=5.894, p<.0005$; Wilks' $\Lambda=.682$; partial $\eta^{2}=.120$. Follow-up univariate ANOVAs were conducted to identify differences in means using a Bonferroni adjusted $\alpha$ level. Tukey post-hoc tests showed a difference between the means for leadership scores $(p=.025)$ and admonishing scores $(p=.011)$. Table 4 provides significant univariate effects for ideal teacher and teacher self-perceptions of communication behaviors.

Table 4: Significant Univariate Effects for Ideal Teacher and Teacher Self-perceptions of Communication Behaviors

\begin{tabular}{|c|c|c|c|c|c|c|}
\hline Independent Variable & $d f$ & $F$ & Teacher & $M$ & Lower Bound & Upper Bound \\
\hline \multirow{2}{*}{ Leadership } & \multirow{2}{*}{3} & \multirow{2}{*}{19.897} & Ideal & 3.74 & 3.46 & 4.02 \\
\hline & & & Self & 3.08 & 2.73 & 3.44 \\
\hline \multirow{2}{*}{ Understanding } & \multirow{2}{*}{3} & \multirow{2}{*}{18.403} & Ideal & 3.57 & 3.25 & 3.90 \\
\hline & & & Self & 2.98 & 2.60 & 3.40 \\
\hline \multirow{2}{*}{ Uncertain } & \multirow{2}{*}{3} & \multirow{2}{*}{4.193} & Ideal & 0.70 & 0.49 & 0.92 \\
\hline & & & Self & 0.92 & 0.64 & 1.20 \\
\hline \multirow{2}{*}{ Admonishing } & \multirow{2}{*}{3} & \multirow{2}{*}{11.690} & Ideal & 0.34 & 0.05 & 0.63 \\
\hline & & & Self & 1.09 & 0.72 & 1.50 \\
\hline \multirow{2}{*}{ Helping/Friendly } & \multirow{2}{*}{3} & \multirow{2}{*}{21.319} & Ideal & 3.70 & 3.38 & 4.01 \\
\hline & & & Self & 3.31 & 2.91 & 3.72 \\
\hline
\end{tabular}

Note: $\alpha<0.00625$; Confidence intervals are $95 \%$.

An independent-samples t-test was conducted to determine mean differences between the dependent variables (teacher self-perceptions and student perceptions) and the independent variables (leadership, understanding, uncertain, admonishing, helping/friendly, student responsibility/freedom, dissatisfied, and strict). There were 27 teacher participants and 209 student participants. Homogeneity of variance was violated likely due to the large difference in group sizes, as assessed by Shapiro-Wilk's test; therefore, the Welch- Satterthwaite correction to the degrees of freedom t-test was used to identify the differences in means (https://statistics.laerd.com). To account for inflation of Type I error, only $p$ values for $0.00625(0.05 / 8)$ were considered significant. 
The independent $t$-test revealed statistically significant differences between teacher self-perceptions of communication behaviors and student perceptions of teacher communication behaviors for leadership scores, $t(123.672)=3.730, p<.0005$; understanding scores, $t(123.672)=3.730, p<.0005$; helping/friendly scores, $t(99.614)=$ $6.094, p<.0005$; and strict scores, $t(85.169)=3.093, p=.003$. Table 5 provides mean differences for teacher self-perceptions of communication behaviors and student perceptions of teacher communication behaviors.

Table 5: Differences in Means between Teacher self-perceptions and Student perceptions of teacher communication behaviors

\begin{tabular}{|c|c|c|c|c|c|c|c|}
\hline Independent Variable & Person & $n$ & $M$ & $S D$ & $t$ & $d f$ & $p$ \\
\hline \multirow{2}{*}{ Leadership } & Teacher Self & 27 & 3.07 & 0.32 & \multirow{2}{*}{3.73} & \multirow{2}{*}{123.67} & \multirow{2}{*}{$<.001^{*}$} \\
\hline & Student & 209 & 2.71 & 1.07 & & & \\
\hline \multirow{2}{*}{ Understanding } & Teacher Self & 27 & 3.01 & 0.35 & \multirow{2}{*}{4.70} & \multirow{2}{*}{137.44} & \multirow{2}{*}{$<.001^{*}$} \\
\hline & Student & 205 & 2.50 & 1.26 & & & \\
\hline \multirow{2}{*}{ Helping/Friendly } & Teacher Self & 29 & 3.30 & 0.47 & \multirow{2}{*}{6.09} & \multirow{2}{*}{99.61} & \multirow{2}{*}{$<.001^{*}$} \\
\hline & Student & 201 & 2.50 & 1.25 & & & \\
\hline \multirow{2}{*}{ Responsibility/Freedom } & Teacher Self & 27 & 1.50 & .041 & \multirow{2}{*}{0.31} & \multirow{2}{*}{68.97} & \multirow{2}{*}{0.759} \\
\hline & Student & 200 & 1.41 & 0.92 & & & \\
\hline \multirow{2}{*}{ Uncertain } & Teacher Self & 29 & 0.95 & 0.61 & \multirow{2}{*}{1.33} & \multirow{2}{*}{40.22} & \multirow{2}{*}{0.190} \\
\hline & Student & 205 & 0.78 & 0.73 & & & \\
\hline \multirow{2}{*}{ Admonishing } & Teacher Self & 30 & 1.01 & 0.49 & \multirow{2}{*}{-2.36} & \multirow{2}{*}{78.51} & \multirow{2}{*}{$0.021^{*}$} \\
\hline & Student & 201 & 1.28 & 1.06 & & & \\
\hline \multirow{2}{*}{ Dissatisfied } & Teacher Self & 30 & 0.96 & 0.5 & \multirow{2}{*}{-0.47} & \multirow{2}{*}{73.22} & \multirow{2}{*}{0.642} \\
\hline & Student & 205 & 1.01 & 1.03 & & & \\
\hline \multirow{2}{*}{ Strict } & Teacher Self & 29 & 2.10 & 0.38 & \multirow{2}{*}{3.10} & \multirow{2}{*}{85.16} & \multirow{2}{*}{$0.003^{*}$} \\
\hline & Student & 202 & 1.80 & 0.92 & & & \\
\hline
\end{tabular}

Note: $\alpha<0.00625,{ }^{*}$ denotes significance

An independent-samples t-test was run to determine if there were differences between the dependent variables (ideal teacher and student perceptions of ideal teacher) communication behaviors and independent variables (leadership, understanding, uncertain, admonishing, helping/friendly, student responsibility/freedom, dissatisfied, and strict). There were 37 teacher participants and 212 student participants. Homogeneity of variance was violated because of sample sizes, as assessed by Shapiro-Wilk's test; therefore, the Welch- Satterthwaite correction to the degrees of freedom t-test was used to identify the differences in means. To account for inflation of Type I error, only $p$ values for $0.00625(0.05 / 8)$ were considered significant.

The independent-samples t-test revealed statistically significant differences between ideal teacher and student perceptions of ideal teacher communication behaviors for leadership scores, $t(105.581)=6.706, p<.0005$; understanding scores, $t(114.949)=5.578, p<$ .0005 ; helping/friendly scores, $t(97.513)=5.331, p<.0005$; admonishing scores, $t(117.515)$ $=-7.123, p<.0005$, and strict scores, $t(62.367)=3.538, p=.001$. Table 6 provides the differences in means between ideal teacher perceptions and student perceptions of ideal teacher communication behaviors. 
Table 6: Differences in Means between Ideal Teacher Perceptions and Student Perceptions of Ideal Teacher Communication Behaviors

\begin{tabular}{|c|c|c|c|c|c|c|c|}
\hline Independent Variable & Ideal & $n$ & $M$ & $S D$ & $t$ & $d f$ & $p$ \\
\hline \multirow{2}{*}{ Leadership } & Ideal Teacher & 37 & 3.72 & 0.33 & \multirow{2}{*}{6.71} & \multirow{2}{*}{105.58} & \multirow{2}{*}{$<.001^{*}$} \\
\hline & Student Ideal & 209 & 3.23 & 0.70 & & & \\
\hline \multirow{2}{*}{ Understanding } & Ideal Teacher & 37 & 3.56 & 0.35 & \multirow{2}{*}{5.58} & \multirow{2}{*}{114.94} & \multirow{2}{*}{$<.001^{*}$} \\
\hline & Student Ideal & 210 & 3.12 & 0.78 & & & \\
\hline \multirow{2}{*}{ Helping/Friendly } & Ideal Teacher & 36 & 3.68 & 0.38 & \multirow{2}{*}{5.33} & \multirow{2}{*}{97.51} & \multirow{2}{*}{$<.001^{*}$} \\
\hline & Student Ideal & 212 & 3.23 & 0.81 & & & \\
\hline \multirow{2}{*}{ Responsibility/Freedom } & Ideal Teacher & 37 & 1.57 & 0.49 & \multirow{2}{*}{-1.49} & \multirow{2}{*}{60.00} & \multirow{2}{*}{0.140} \\
\hline & Student Ideal & 202 & 1.71 & 0.62 & & & \\
\hline \multirow{2}{*}{ Uncertain } & Ideal Teacher & 37 & 0.77 & 0.43 & \multirow{2}{*}{2.00} & \multirow{2}{*}{57.00} & \multirow{2}{*}{0.050} \\
\hline & Student Ideal & 210 & 0.61 & 0.53 & & & \\
\hline \multirow{2}{*}{ Admonishing } & Ideal Teacher & 36 & 0.38 & 0.34 & \multirow{2}{*}{-7.12} & \multirow{2}{*}{117.52} & \multirow{2}{*}{$<.001^{*}$} \\
\hline & Student Ideal & 209 & 0.94 & 0.80 & & & \\
\hline \multirow{2}{*}{ Dissatisfied } & Ideal Teacher & 37 & 0.68 & 0.43 & \multirow{2}{*}{-0.21} & \multirow{2}{*}{76.35} & \multirow{2}{*}{0.840} \\
\hline & Student Ideal & 209 & 0.70 & 0.72 & & & \\
\hline \multirow{2}{*}{ Strict } & Ideal Teacher & 37 & 1.97 & 0.52 & \multirow{2}{*}{3.53} & \multirow{2}{*}{62.37} & \multirow{2}{*}{$0.001^{*}$} \\
\hline & Student Ideal & 205 & 1.61 & 0.71 & & & \\
\hline
\end{tabular}

Note: $\alpha<0.00625,{ }^{*}$ denotes significance.

\section{Discussion}

The quantitative study was designed to address the following research questions:

1) What relationship exists between student and teacher perceptions of communication behaviors that affect the teacher-student relationship?

2) Is there a difference between ideal teacher communication behaviors and teacher self- perceptions of communication behaviors in the classroom?

3) Is there a difference between teacher self-perceptions of communication behaviors and student perceptions of teacher communication behaviors in the classroom?

4) Is there a difference between ideal teacher communication behaviors and student perceptions of ideal teacher communication behaviors in the classroom?

In order to answer these questions, it was necessary to measure student perceptions of communication behaviors and teacher perceptions of communication behaviors found in the middle school setting. The Questionnaire on Teacher Interaction (QTI) survey was utilized to measure four different viewpoints of communication behaviors seen in the classroom. Two of the surveys focused on ideal teacher communication behaviors from a teacher and student perspective. Two of the surveys focused on actual teacher communication behaviors perceived in the classroom from the teacher and student vantage point. Thirty-seven teachers participated in the ideal teacher communication behaviors survey, 30 teachers chose to partake in the teacher self-perception of communication behaviors survey, and 218 students chose to participate in both student surveys.

Multivariate analysis of variance (MANOVA) tests identified significant univariate effects for leadership, understanding, uncertain, admonishing, and 
helping/friendly scores between ideal teacher communication behaviors and teacher selfperceptions of communication behaviors in the middle school setting. This statistical method was chosen because there are eight independent variables (leadership, understanding, uncertain, admonishing, helping/friendly, student responsibility/freedom, dissatisfied, and strict) and two dependent variables (ideal and teacher self-perceptions).

Follow-up analysis of variance (ANOVA) tests were conducted to identify specific differences in communication behaviors. Results indicate a statistically significant difference between ideal teacher and teacher self-perceptions of communication behaviors for leadership and admonishing scores. An analysis of this could be that teachers believe the ideal teacher would exhibit more leadership qualities such as: explaining things clearly, acting confidentially, holding attention, and talking enthusiastically about his/her subject, instead of showing anger behaviors. These findings are similar to a study conducted by Wubels, Brekelmans, Creton, \& Hooymayers (1990), which revealed that teachers desired to increase leadership skills and exhibit less angry behaviors in the classroom. To date, a minimal number of research studies have utilized the ideal teacher and teacher self-perceptions of communication behaviors surveys in the middle school setting; therefore, it is difficult to compare this study's findings to others.

An independent-samples t-test was conducted to determine the differences in communication behaviors between teacher self-perceptions and student perceptions based on the eight independent variables as previously discussed. From the survey, teachers consider themselves to exhibit more leadership, understanding, helping/friendly and strict behaviors than their students perceived. These findings are congruent with past research regarding teacher communication behaviors (Khine \& Atputhasamy, 2003; Fraser, Aldridge, \& Soerjaningsih, 2010; Wubbels, Levy, \& Brekelmans, 1997).

An independent-samples t-test was conducted to identify the differences in communication behaviors between ideal teacher communication behaviors and student perceptions of ideal teacher communication behaviors. Again, the same eight constructs were tested to identify the differences in means. Findings revealed a significant difference in means between leadership, understanding, helping/friendly, admonishing, and strict scores. Out of these findings, students' mean scores for admonishing behavior was significantly higher than teachers' scores. This could be due to the fact that students perceive all teachers to portray anger or impatient behaviors. These conclusions are congruent with the findings from Henderson, Fisher, and Fraser's (1994) international study, along with Britt's (2013) recent dissertation study.

\subsection{Future Studies}

Overall results cast a new light on teachers' communication behaviors and how they are perceived by themselves and others. Clearly the teachers interviewed in this study neglected to believe their attitude and demeanor had little to no effect on students' behaviors. However, qualitative results from student interviews suggest that teachers are unaware of their actions or refuse to believe student behavior could stem from theirs. An 
example of this was given from a student who knew his teacher did not like him because of the way he was treated differently from other students in the class. Little to no evidence of this instance was described from the teacher interviews. These findings correlate with a recent study which identified the need for further research on teacher reporting of behavior versus student narratives (Donker, et. al., 2021). Therefore, future studies should consider the potential effects of teachers' perceptions of communication behaviors more carefully. Ideally, one should build a study around live observations of teacherstudent interactions in hopes of shedding light on how the display of behaviors could possibly alter communication between the teacher and the student. Gaining knowledge from a different perspective and an outside viewer might encourage teachers to selfassess difficult situations and identify ways to facilitate change. Future research could also explore teacher-student relationships in urban areas, elementary, high school, or collegiate levels, and socioeconomic status.

\section{Conflict of Interest Statement}

The authors declare no conflicts of interests.

\section{About the Author}

Dr. Kelli Smith - Assistant Professor of Elementary Education at Auburn University at Montgomery. Her area of expertise is building positive teacher-student relationships.

\section{References}

Allen, J., Gregory, A., Mikami, A., Lun, J., Hamre, B., \& Pianta, R. (2013). Observations of effective teacher-student interactions in secondary school classrooms: Predicting student achievement with the classroom assessment scoring system-secondary. School Psychology Review, 42(1), 76-98.

Anderson, D. H., Nelson, J. A., Richardson M., Webb, N., \& Young, E. L. (2011). Using dialogue journals to strengthen the student-teacher relationship: A comparative case study. College Student Journal. 45(2), 269-287.

Andrews, C., \& Bishop, P. (2012). Middle grades transition programs around the globe. Middle School Journal, 44(1), 8-14.

Bush, S., \& Godden, E. (2019). Relationship-building from day one: A simple technique to build rapport and recognise new students' needs. Impact (2514-6955), 5, 22-23.

Creswell, J. W., \& Plano Clark, V. L. (2011). Designing and conducting mixed-methods research ( $2^{\text {nd }}$ ed), Thousand Oaks, CA: Sage Publications.

Costa Johansen, T. A. (2017). Teacher-level factors that influence student discipline decisions, or "you can't back a middle school kid into the corner" [ProQuest Information \& Learning]. In Dissertation Abstracts International Section A: Humanities and Social Sciences (Vol. 77, Issue 10-A(E)). 
Donker, M. H., Vemde, L. van, Hessen, D. J., Gog, T. van, \& Mainhard, T. (2021). Observational, student, and teacher perspectives on interpersonal teacher behavior: Shared and unique associations with teacher and student emotions. Learning and Instruction, 73. https://doi.org/https://doi.org/10.1016/j.learninstruc.2020.101414

Daniels, E. \& Arapostathis, M. (2005). What do they really want? Students' voices and motivational research. Urban Education, 40(1), 34-59.

Eupena, R. G. (2012). Teacher communication behavior: It's impact to the students' attitude in learning science. International Journal of Social Sciences, 3(1), 147-163.

Ferreira, M. M., \& Bosworth, K. (2001). Defining caring teachers: Adolescents' perspectives. Journal of Classroom Interaction, 36(1), 24-30.

Fefer, S. A., \& Gordon, K. (2020). Exploring Perceptions of School Climate among Secondary Students with Varying Discipline Infractions. International Journal of School \& Educational Psychology, 8(3), 174-183.

Fraser, B. J., Aldridge, J. M., \& Soerjaningsih, W. (2010). Instructor-student interpersonal interaction and student outcomes at the university level in Indonesia. The Open Education Journal, 3(1), 21-33.

Gehlbach, H., Brinkworth, M. E., \& Harris, A. D. (2012). Changes in teacher-student relationships. British Journal of Educational Psychology, 82(4), 690-704.

Gutierrez, A. S., Buckley, K. H., \& Transforming Education. (2019). Stories from the Field: Building Strong Teacher-Student Relationships in the Classroom. In Transforming Education. Transforming Education.

Hamre, B. K., \& Pianta, R. C. (2006). Student-Teacher Relationships. In G. G. Bear \& K. M. Minke (Eds.), Children's needs III: Development, prevention, and intervention (p. 5971). National Association of School Psychologists.

Ibrahim, A., \& El Zataari, W. (2020). The teacher-student relationship and adolescents' sense of school belonging. International Journal of Adolescence and Youth, 25(1), 382395. https://doi-org.libproxy.aum.edu/10.1080/02673843.2019.1660998

Kesner, J. E. (2000). Teacher characteristics and the quality of child-teacher relationships. Journal of School Psychology, 28(2), 133-149.

Kvale, S. \& Brinkmann, S. (2009) InterViews: Learning the Craft of Qualitative Research Interviewing ( $2^{\text {nd }}$ ed), London: Sage Publications.

Leary, T. (1957). Interpersonal diagnosis of personality: A functional theory and methodology for personality evaluation. Ronald Press.

Lewis, C., Enciso, P., \& Moje, E. B. (2009). Reframing sociocultural research on literacy: Identity, agency, and power. New York, NY: Routledge.

Martinez, R. S., Aricak, O. T., Graves, M. N., Peters-Myszak, J., \& Nellis, L. (2011). Changes in perceived social support and socioemotional adjustment across the elementary to junior high school transition. Journal of Youth $\mathcal{E}$ Adolescence, 40(5), 519- 530. 
Newcomer, S. N. (2018). Investigating the Power of Authentically Caring StudentTeacher Relationships for Latinx Students. Journal of Latinos E Education, 17(2), 179-193. https://doi-org.libproxy.aum.edu/10.1080/15348431.2017.1310104

Pennings, H. J. M., \& Hollenstein, T. (2020). Teacher-Student Interactions and Teacher Interpersonal Styles: A State Space Grid Analysis. Journal of Experimental Education, 88(3), 382-406.

Sakiz, G., Pape, S. J., \& Hoy, A. W. (2012). Does perceived teacher affective support matter for middle school students in mathematics classrooms? Journal of School Psychology, 50(2), 235-255.

Shukla, K. D., Kuril, S., \& Chand, V. S. (2020). Does negative teacher behavior influence student self-efficacy and mastery goal orientation? Learning and Motivation, 71. https://doi-org.libproxy.aum.edu/10.1016/j.lmot.2020.101653

Tosolt, B. (2009). Middle school students' perceptions of caring teacher behaviors: Differences by minority status. The Journal of Negro Education, 78(4), 405-416.

Woolley, M. E., Strutchens, M. E., Gilbert, M. C., \& Martin, W. G. (2010). Mathematics success of black middle school students: Direct and indirect effects of teacher expectations and reform practices. The Negro Education Review, 61(1-4), 41-59.

Wubbels, T., Brekelmans, M., den Brok, Pl, van Tartwijk, J. (2006). An interpersonal perspective on classroom management in secondary classrooms in the Netherlands. Handbook of classroom management: research, practice and contemporary issues, pp. $1161-1191$.

Wubbels, T., Levy, J., \& Brekelmans, M. (1997). Paying attention to relationships. Educational Leadership, 54(7), 82-86. 

to copy, distribute, transmit or adapt the article content, providing a proper, prominent and unambiguous attribution to the authors in a manner that makes clear that the materials are being reused under permission of a Creative Commons License. Views, opinions and conclusions expressed in this research article are views, opinions and conclusions of the author(s). Open Access Publishing Group and European Journal of Education Studies shall not be responsible or answerable for any loss, damage or liability caused in relation to/arising out of conflicts of interest, copyright violations and inappropriate or inaccurate use of any kind content related or integrated into the research work. All the published works are meeting the Open Access Publishing requirements and can be freely accessed, shared, modified, distributed and used in educational, commercial and non-commercial purposes under a Creative Commons Attribution 4.0 International License (CC BY 4.0). 